\title{
COVID-19 in Healthcare Workers and Serving Safe Healthcare During the Pandemic
}

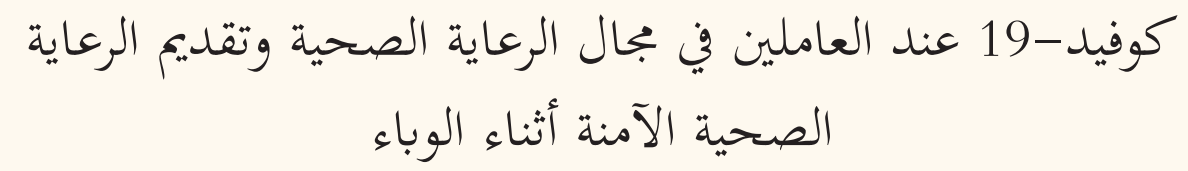

أمل سيف المعنية وسيف سالم العبري

C ORONAVIRUS DISEASE 2019 (COVID-19), CAUSED by the severe acute respiratory syndrome (SARS)-CoV-2 virus, was declared by the World Health Organization as a pandemic on March 11, 2020 to highlight the gravity of a unique healthcare experience that had not been previously experienced since 1918 with the Spanish flu pandemic. The increased demand on the healthcare facilities in providing medical care during pandemics creates unique challenges of providing care while ensuring the safety of vulnerable patients and healthcare workers (HCWs). HCWs are the most important resource in controlling the spread and propagation of the pandemic but they can also be the source for healthcare outbreaks and ongoing community transmission.

Throughout the history of coronavirus outbreaks and epidemics, the personnel working in healthcare institutions have rarely been spared. In 2003, the SARS epidemic quickly spread worldwide with a great proportion of those with the disease being associated with hospital-based outbreaks. ${ }^{1,2}$ The infected HCWs accounted for $37 \%-63 \%$ of suspected SARS cases in highly affected countries forcing hospital closure and mandatory quarantine., In 2012, the second coronavirus epidemic emerged as the Middle East respiratory syndrome coronavirus (MERS-CoV) which, by the end of November 2019, resulted in a total of 2,494 laboratory-confirmed cases globally and associated deaths (case fatality rate: $34.4 \%$ ). 5 The overall proportion of MERS-CoV infected HCWs was 25\%, which varied significantly by outbreak from $13-89 \% \quad(P<0.001)$. Interestingly, $70 \%$ of asymptomatic infections were reported among $\mathrm{HCW}$ s with no fatalities. ${ }^{6}$ In Oman, a total of 24 cases of MERS-COV were reported from 2013 to the end of 2019 including two mild cases in HCWs from two separate nosocomial outbreaks and the associated deaths (case fatality rate: $29.2 \%)$.
In the early phase of the COVID-19 pandemic, data from Wuhan, China, up to 24 February 2020, showed that of 77,262 patients there were 3,387 infected HCWs (4.4\%); 23 of these individuals had died by April of the same year. ${ }^{8}$ In a study from Wuhan, the source of $\mathrm{HCW}$ infection was found to be contact with infected colleagues $(\mathrm{n}=12,10.9 \%)$ while 14 ( $(12.7 \%)$ were attributed to community acquisition. ${ }^{9}$ In areas where community transmission was established, a healthcare cluster was more likely due to lapse in early HCW case detection. This is particularly significant in COVID-19 because patients may have mild atypical symptoms and there could be pre-symptomatic transmission. ${ }^{10} \mathrm{~A}$ study of two Dutch hospitals found that out of 9,705 HCWs of which 1,353 were tested for COVID-19, a total of $86(6 \%)$ were infected with SARS-CoV2 out of which only $3(3 \%)$ had been exposed to an admitted confirmed COVID-19 inpatient and that a substantial proportion of HCWs were infected with SARSCoV-2 two weeks prior. ${ }^{11}$ The first case was admitted to the facility which indicated that their exposure was most likely in the community. ${ }^{11}$ In a Morbidity and Mortality Weekly Report from the Centers for Disease Control and Prevention (CDC), $121 \mathrm{HCWs}$ were exposed to a patient with unrecognised COVID-19 of which 43 became symptomatic; only three were positive for SARS$\mathrm{CoV}-2$ and all three had had unprotected patient contact. ${ }^{12}$

In the USA, as of 6 June 2020, it had been reported that nearly 600 frontline HCWs died due to COVID-19.13 A study from the UK and USA estimated that frontline HCWs had a 3.4 fold higher risk than people living in the general community for reporting a positive test, adjusting for the likelihood of receiving a test. ${ }^{14}$

Other studies however, reported lower illness severity in HCWs and identified personal protective equipment (PPE) use as a main factor associated with decreased infection risk. ${ }^{15} \mathrm{~A}$ retrospective study including $72 \mathrm{HCWs}$ 
rom a large hospital in Wuhan found that suboptimal hand hygiene, longer duty hours and working in a high-risk department were associated with contracting COVID-19.16 The European CDC analysed data in May 2020 from 15 countries including the UK and found that $23.2 \%(n=43,774)$ of COVID-19 cases were among HCWs; only 9\% of HCWs required hospitalisation compared to $17 \%$ of non-HCWs. Furthermore, $1 \%$ of HCWs presented with severe illness (intensive care unit [ICU] admission or respiratory support required) compared to $5 \%$ in non-HCWs. ${ }^{17}$ After gender and age-adjusted analysis, hospitalised $\mathrm{HCW}$ s were still less likely to require ICU admission and had a lower case fatality than non-HCWs. ${ }^{17}$ In Oman, the number of infected medical doctors and nurses until the end of July 2020 (total confirmed cases nationally: 79,159) were $192(0.2 \%)$ and $508(0.6 \%)$, respectively. Four HCWs needed ICU care and there was one fatality of a 70-year-old physician (Personal communication, Directorate General for Disease Surveillance and Control, Ministry of Health, Oman). HCWs generally have more access and prioritisation for testing and healthcare which facilitates diagnosis and hospitalisation at earlier stages and/or with milder signs and symptoms suggesting that these observed differences could be related to the "healthy worker effect.' ${ }^{18}$ A study looking at different occupations in six Asian countries and the risk of COVID-19 found that infection in HCWs accounted for 3\% compared to $12 \%$ in non-HCWs of local reported cases and in all included countries; the first cases in HCWs appeared much later than the first non-HCW cases. ${ }^{19}$ The study suggested that this likely reflects improved triage, screening and isolation of COVID-19 patients, availability of PPE and overall better knowledge and practice of hygiene and infection control within healthcare facilities. ${ }^{19}$

Transmission of a respiratory infection to HCWs may also be event-dependent. Aerosol generating procedures (AGPs), such as intubations and medication nebulisers, have been associated with healthcarerelated outbreaks, even among protected HCWs. A cluster of SARS in nine HCWs from Toronto, Canada, developed after they cared for a patient around the time of intubation, despite use of full PPE. ${ }^{3}$ In the USA, although many healthcare workers had unprotected exposures, no documented transmission of SARS-CoV was found; this is probably due to relative absence of highly infectious patients or highrisk patient procedures. ${ }^{4}$ A recent analysis by the Respiratory Protection Effectiveness Trial suggests the risk of HCWs becoming infected with an endemic coronavirus increases approximately two-fold with exposures to AGPs. ${ }^{20}$
A number of insights and lessons were gained from the experience with previous coronavirus epidemics (SARS and MERS) and the current COVID-19 pandemic that will help mitigate the risk of $\mathrm{HCW}$ infection and help to serve safe healthcare during the next phase of this unique situation. Rapid identification and isolation of potentially infectious cases is the key measure in minimising exposures and interrupting the chain of transmission. The implementation of triage systems for infectious diseases in an emergency and outpatient setting is one of the administrative strategies that can ensure rapid identification and isolation; this strategy was implemented early in Oman's healthcare facilities during the current pandemic. Communication between public health officials and hospital infection control staff can help enable efficient implementation of control procedures especially where most of the transmission is community driven. The current levels of PPE (i.e. gown/apron, surgical mask, face-shield/ goggles and gloves), engineering and administrative control may not be sufficient if many high-risk patients or procedures qualify for airborne set-up. Unprotected exposure among HCWs may still occur despite the implementation of facility-wide masking in the absence of administrative and engineering control. Therefore, new initiatives for infection control should include measures to improve HCWs' understanding of infection control science and risk assessment principles so that more cost-effective approaches can be implemented, specifically focusing on patients and events that have the highest risk for transmission.

\section{References}

1. Lee N, Hui D, Wu A, Chan P, Cameron P, Joynt GM, et al. A major outbreak of severe acute respiratory syndrome in Hong Kong. N Engl J Med 2003; 348:1986-94. https://doi. org/10.1056/NEJMoa030685.

2. Ruan YJ, Wei CL, Ee AL, Vega VB, Thoreau H, Su ST, et al. Comparative full-length genome sequence analysis of 14 SARS coronavirus isolates and common mutations associated with putative origins of infection. Lancet 2003; 361:1779-85. https:// doi.org/10.1016/s0140-6736(03)13414-9.

3. Centers for Disease Control and Prevention. Cluster of severe acute respiratory syndrome cases among protected health-care workers-Toronto, Canada, April 2003. MMWR Morb Mortal Wkly Rep 2003;52:433-6.

4. Peck AJ, Newbern EC, Feikin DR, Issakbaeva ET, Park BJ, Fehr J, et al. Lack of SARS transmission and U.S. SARS case-patient. Emerg Infect Dis 2004; 10:217-24. https://doi.org/10.3201/ eid1002.030746.

5. World Health Organization. MERS situation update report November 2019. From: http://www.emro.who.int/pandemicepidemic-diseases/mers-cov/mers-situation-updatenovember-2019.html Accessed: Nov 2020

6. Bernard-Stoecklin S, Nikolay B, Assiri A, Bin Saeed AA, Ben Embarek PK, El Bushra H, et al. Comparative analysis of eleven healthcare-associated outbreaks of middle east respiratory syndrome coronavirus (Mers-Cov) from 2015 to 2017. Sci Rep 2019; 9:7385. https://doi.org/10.1038/s41598-019-43586-9. 
7. World Health Organization. Middle East respiratory syndrome coronavirus (MERS-CoV) - Oman, Disease outbreak news 4 March 2019. From: https://www.who.int/csr/don/04-march2019-mers-oman/en/ Accessed: Nov 2020.

8. Zhan M, Qin Y, Xue X, Zhu S. Death from Covid-19 of 23 health care workers in China. N Engl J Med 2020; 382:2267-8. https://doi.org/10.1056/NEJMc2005696.

9. Lai X, Wang M, Qin C, Tan L, Ran L, Chen D, et al. Coronavirus disease 2019 (COVID-2019) infection among health care workers and implications for prevention measures in a tertiary hospital in Wuhan, China. JAMA Netw Open 2020; 3:e209666. https://doi.org/10.1001/jamanetworkopen.2020.9666.

10. Wei WE, Li Z, Chiew CJ, Yong SE, Toh MP, Lee VJ. Presymptomatic transmission of SARS-CoV-2 - Singapore, January 23-March 16, 2020. MMWR Morb Mortal Wkly Rep 2020; 69:411-15. https://doi.org/10.15585/mmwr.mm6914e1.

11. Kluytmans-von den Bergh MFQ, Buiting AGM, Pas SD Bentvelsen RG, van den Bijlaardt W, van Oudheusden AJG, et al. SARS-CoV-2 infection in 86 healthcare workers in two Dutch hospitals in March 2020. Medrxiv 2020. https://doi.org/ 10.1101/2020.03.23.20041913.

12. Heinzerling A, Stuckey MJ, Scheuer T, Xu K, Perkins KM, Resseger H, et al. Transmission of COVID-19 to health care personnel during exposures to a hospitalized patient - Solano County, California, February 2020. MMWR Morb Mortal Wkly Rep 2020; 69:472-6. https://doi.org/10.15585/mmwr. mm6915e5.

13. Jewett C, Bailey M, Renwick D. Exclusive: Nearly 600 - And Counting - US Health Workers Have Died Of COVID-19. From: https://khn.org/news/exclusive-investigation-nearly600-and-counting-us-health-workers-have-died-of-covid-19/ Accessed: Nov 2020
14. Nguyen LH, Drew DA, Joshi AD, Guo CG, Ma W, Mehta RS, et al. Risk of COVID-19 among frontline healthcare workers and the general community: A prospective cohort study. medRxiv [Preprint] 2020: 2020.04.29.20084111. https://doi.org /10.1101/2020.04.29.20084111.

15. Chou R, Dana T, Buckley DI, Selph S, Fu R, Totten AM. Epidemiology of and risk factors for coronavirus infection in health care workers: A living rapid review. Ann Intern Med 2020; 173:120-36. https://doi.org/10.7326/M20-1632.

16. Ran L, Chen X, Wang Y, Wu W, Zhang L, Tan X. Risk factors of healthcare workers with coronavirus disease 2019: A retrospective cohort study in a designated hospital of Wuhan in China. Clin Infect Dis 2020; 71:2218-21. https://doi. org/10.1093/cid/ciaa287.

17. European Centre for Disease Prevention and Control. Epidemiology of COVID-19. From: https://www.ecdc.europa. eu/en/covid-19/latest-evidence/epidemiology Accessed: Aug 2020

18. Monson RR. Observations on the healthy worker effect. J Occup Med 1986; 28:425-33. https://doi.org/10.1097/00043764-19860 6000-00009

19. Lan FY, Wei CF, Hsu YT, Christiani DC, Kales SN. Workrelated COVID-19 transmission in six Asian countries/areas: A follow-up study. PLoS One 2020; 15:e233588. https://doi. org/10.1371/journal.pone.0233588.

20. Cummings DAT, Radonovich LJ, Gorse GJ, Gaydos CA, Bessesen MT, Brown AC, et al. Risk factors for healthcare personnel infection with endemic coronaviruses (HKU1, OC43, NL63, 229E): Results from the Respiratory Protection Effectiveness Clinical Trial (ResPECT). Clin Infect Dis 2020; ciaa900. https://doi.org/10.1093/cid/ciaa900. 